\title{
Improving physician flow and efficiency in the emergency department
}

\author{
Christopher J. Denny, MD; ${ }^{*}$ Brian D. Steinhart, MD; ${ }^{\dagger}$ Richard Yu, MD ${ }^{\dagger}$
}

"We are what we repeatedly do. Excellence, then, is not an act, but a habit."

- Aristotle

\section{Introduction}

As an emergency physician, one of the cardinal skills to acquire is the ability to successfully manage large patient loads in a busy emergency department (ED). Such successful management requires speed and efficiency in managing patient flow, especially in light of our present state of overcrowding. Physician efficiency is a highly respected, yet rarely taught skill. In the "2001 Model of the Clinical Practice of Emergency Medicine," Hockberger and colleagues ${ }^{1}$ define emergency physician tasks to include "performance of focused history and physical examination, and multitasking and team management."

Numerous factors may contribute to an efficient ED. Systemic processes are increasingly studied under the headings of human factors engineering, or workplace ergonomics. ${ }^{2-4}$ These efforts aim to study how human beings interact with their environment (in this case the ED) for useful purposes. Other researchers describe the possibilities of using computerized notepads and other personal data assistants (PDAs) to increase efficiency. ${ }^{5}$ In both the nursing and surgical literature, the issue of workplace efficiency has been considered. ${ }^{6,7}$ Within emergency medicine, ED workplace interruptions have been assessed. ${ }^{8}$ Little has been written on physician efficiency in the ED. Beel ${ }^{9}$ offers several suggestions on moving faster as a clinician. Neither evidence nor references are given to support his ideas.

We believe emergency physician efficiency is a skill that can be taught and refined. In May 2000, the Society for Academic Emergency Medicine (SAEM) sponsored a conference on errors in emergency medicine. We contest the assertion made by Vincent and coworkers ${ }^{10}$ in the executive summary of the SAEM Errors Conference that "individual practitioners may be approaching or have exceeded the speed-accuracy trade-off under increasing production pressures". No one has compared the relative benefits of individual clinician efficiency versus process efficiency, nor have they examined the threshold between speed and error.

Increased physician efficiency may serve three important goals. First, it may help increase patient satisfaction by decreasing waiting times as patient flow increases. Systems changes have been shown to reduce patients' length of stay. ${ }^{11,12}$ Second, it may free time from routine cases to focus on critically ill patients, by eliminating time-wasting and energy-draining inefficiencies. Third, if we link efficiency with improving teamwork, we may decrease medical errors. ${ }^{13}$

Although many factors are beyond our immediate control as physicians, several strategies may increase our efficiency. Croskerry ${ }^{14}$ has done pioneering work in analyzing how emergency physicians think and make clinical decisions. He emphasizes the "density of decision making" within the milieu of the ED. We will not be focusing on clinical reasoning strategies.

This paper grew out of discussions between a senior resident (C.J.D.) and 2 experienced attending physicians in emergency medicine (B.D.S., R.Y.). It was further informed by suggestions emanating from a workshop presented at the University of Toronto and Royal College of Physicians and Surgeons of Canada Emergency Medicine Resident \& Faculty Retreat held in Caledon, Ont., in early

From the *Royal College Emergency Medicine Residency, and the tDepartment of Emergency Medicine, St. Michael's Hospital, University of Toronto, Toronto, Ont.

Received: Feb. 4, 2003; final submission: May 6, 2003; accepted: May 6, 2003

This article has been peer reviewed.

Can J Emerg Med 2003;5(4):271-4 
2002. Our paper is not meant to be a systematic review. Although much of this information may benefit resident physicians, it is our sincere hope that our strategies are useful to experienced clinicians as well.

\section{Strategies}

We have constructed specific strategies for each of 3 general categories of clinician expertise. Our classification system consists of physical strategies, cognitive strategies, and strategies for reaching a patient's disposition.

\section{Physical strategies}

1. Carry the tools you need:

- The "obvious": stethoscope, pen, trauma shears, eye protection.

- Prescription pad, highlighter, clipboard, discharge summaries, outpatient appointment information.

- Improvise. Clearly, carrying all possible medical instruments would decrease your speed. Instead, perhaps your trauma shears can double as a reflex hammer.

\section{Embrace technology:}

- Mobile ("Companion”) phone: Allows open channels of communication with the triage and charge nurses, other physicians and administrative assistants. These communication devices operate within the hospital phone network.

- PDAs: Allows point-of-care searching for drug-drug interactions, drug doses, and procedures. Newer models may include a digital camera suitable for medical photography.

- Electronic, modifiable discharge summaries and follow-up instructions. These can be sent home with the patient to communicate with their primary care physician.

- Do the laboratory investigations yourself in the ED when the answers they provide will facilitate patient dispositions: Urine B-hCG, urinalysis, and joint aspiration for crystals. However, if ancillary services provide rapid and reliable turnaround times for these investigations, consider the opportunity cost in doing them yourself.

\section{Minimize unnecessary interruptions:}

- The problem: Coiera and colleagues ${ }^{15}$ observed significant communication loads on ED staff. They measured 11 interruptions per hour, emphasizing the potential for disruption and subsequent diminished efficiency.

- Openly communicate guidelines for interruptions with other members of the ED health care team (e.g., emergency medical services [EMS], nurse practitioner, physician assistant, registered nurse [RN], social work).

- Treat interruptions as red flags that may hinder your clinical decision-making. ${ }^{8}$ Red flags are warning signs that your clinical reasoning is in danger of distraction or derailment.

\section{Streamline your movements:}

- Group tasks and plan your route through the ED: review diagnostic imaging, then lab results.

- Multi-task: While on your way to review some diagnostic imaging, drop off a clinic referral to patient A and give patient $\mathrm{B}$ an $\mathrm{X}$-ray requisition.

- Anticipate needs: Stock a small dispensary of nonnarcotic analgesia in the ambulatory care area.

\section{Recognize limited resources of energy:}

- Early recognition of basic human needs can solve many minor patient problems. A ready supply of hospital-grade sandwiches and other snacks may help to satisfy the appetites of patients enduring long waits in the ED.

- Consider the impact of proper hydration and nutrition in maintaining your optimum performance.

- Plan breaks. Short windows of time to attend to basic needs may help recharge and refocus the clinician. This is especially important with severe acute respiratory syndrome (SARS) and the resultant personal protective equipment we presently wear.

\section{Cognitive strategies}

1. Visualization:

- Time-line projection:

- Attempt to visualize a patient's journey beginning outside the hospital, continuing through the ED, and carrying on either in hospital or back in the community. The more we know about this journey, the better we are able to manage our patient.

- Recognize and seek to understand the patient's (and the family's) agenda(s). There may be overlapping motives of fear, pain, placement and need.

2. Timing (operational):

- Recognize rate-limiting steps:

- For example: You pick up a chart for a dyspneic, febrile patient. Working from a provisional diagnosis of pneumonia, you need to perform a history and physical examination, obtain a chest radiograph (CXR) and an arterial blood gas (ABG). 
Recognizing that the CXR and ABG are the ratelimiting steps in managing this patient, you have the unit clerk enter a radiology requisition while the nurse brings an ABG kit to the bedside, before you commence the focused history and physical examination.

- Be aware of "business hours" for consultation services, diagnostic services (e.g,. ultrasound) and other health care professionals (social work, physiotherapy, research nurses). Anticipate bottlenecks. For example, if diagnostic services diminish to "oncall" status at 1600 , at 1530 conduct "ultrasound rounds" to determine who need this imaging modality. However, excessive testing predicated solely on resource availability may raise costs and increase patient length of stay.

\section{Eyes wide open:}

- Gather first-hand information whenever possible. Listen to EMS handover reports and to RN signover.

- Call early for charts and records from other health care providers (hospitals, primary care physicians, pharmacies). If possible, help to create a system where charts are automatically called for, and EMS reports make it onto the ED chart.

4. Maintain flow:

- If all patients are stable, initiate simple cases before engaging more complex ones. For example, dilate the eye for the retina you need to visualize, freeze the laceration you plan to close, then initiate your assessment of the 92-year-old patient complaining of feeling "weak and dizzy" for the past decade.

5. Delegate effectively to physician extenders:

- Recognize their tremendous worth. Reward your teammates (with praise and with coffee).

- Frontload ancillary services when necessary. Empower social work and other teammates to case find, starting on their clinical assessments prior to physician assessment when warranted.

- Off-load your clerical and administrative tasks where and when it is appropriate.

\section{Dispositions}

\section{Set the stage at the initial encounter:}

- Recognize the inevitable disposition early on: An elderly patient who cannot walk and lives alone requires an admission. Initiate this process as soon as you recognize its need. As Shem ${ }^{16}$ wrote facetiously in his novel The House of God: "Rule 5: Placement comes first."

- Establish a realistic time-line with patients during the initial visit to their stretcher.

- Prepare them for your planned disposition (e.g., this is what will happen if the tests are negative and you are well enough to go home).

2. Strive to make a decision regarding disposition by 4 hours after patient is seen:

- Recognize the limitations of the ED. We provide episodic acute care to our patients.

- Enable a diagnostic strategy that provides you with the information you need to make a decision by this point in the patient's visit:

- Beware of asking a patient a question if you do not want to deal with the answer.

- Order the necessary tests early.

- Only order tests that will affect the patient's management in the ED.

3. Consultations:

- When communicating with a consultant, within the first minute provide:

- the bottom line (i.e., level of acuity)

- a short patient profile

- your clinical impression

- what the patient now requires.

4. Be flexible:

- If general medicine is overwhelmed, perhaps cardiology can admit the patient with congestive heart failure.

\section{Limitations}

These elements of emergency physician performance have not been subjected to quantitative research. Instead, these clinical pearls represent decades of "experience-based medicine." One of the benefits of experience is in gaining awareness of where you can safely "cut" corners to gain efficiency, without increasing error. Nevertheless, our literature review suggests that physician efficiency has scarcely been studied.

Is there a threshold after which increasing speed and efficiency is offset by a decrease in performance and an increase in cost and in the risk of medical error? Moreover, will patients appreciate our efforts or will they perceive a physician treating them like objects on an assembly line?

It is crucial to recognize that physician efficiency is only 
one piece of the puzzle. Medical error, clinical decisionmaking, ED design, human factors engineering, nursing performance, hospital restructuring and prehospital interventions combine to affect the patient's journey through the ED. Any meaningful solution will require transdisciplinary input and collaboration.

\section{Future directions}

Although physician efficiency is often seen as part of the "art of medicine," more rigorous evaluation of how it is taught and practised may help to disseminate best practices. To begin, we might directly observe experienced and less experienced physicians in the ED. Hollingsworth and colleagues ${ }^{17}$ used observational time-and-motion studies to compare how physicians and nurses spend their time in the ED. They note faculty physicians spend less time charting and walk less than resident physicians.

Videotaping trauma resuscitations has been shown to be an effective teaching technique. ${ }^{18}$ Would this technique also work outside of the trauma room? Another option is to design and implement an efficiency curriculum for residents during their training. These studies would help to answer the questions of whether efficiency can be taught, and whether experience counts toward improving physician efficiency.

In the future, might we compare individual emergency physician performance against some benchmark? DeBenhnke and cohorts ${ }^{19}$ compared emergency medicine resident productivity and found performance increased with level of experience. We need to test whether changes in emergency physician speed lead to a difference in outcomes (i.e., more patients seen per hour, and/or decreased waiting times). While this paper focuses on potential improvements in emergency physician efficiency, ED efficiency requires a broader approach considering both ED team function and systems design.

With the current crisis of overcrowding in the ED, it is easy for the clinician to feel incapable of effecting change in the system. While advocating for such change is laudable, each of us can work to improve our personal efficiency, and find satisfaction in the difference we see as we negotiate the chaos of the ED.

\section{Competing interests: None declared.}

Acknowledgements: Dr. Denny is a Province of Ontario Ministry of Health and Long-Term Care Emergency Health Services Research Fellow. The opinions expressed in the paper are solely the authors', and do not represent the opinion of the Government of Ontario.

We thank Drs. Daniel Cass and Michael Schull for their thoughtful comments during the revision of this manuscript.

\section{References}

1. Hockberger RS, Binder LS, Graber MA, Hoffman GL, Perina DG, Schneider SM, et al; American College of Emergency Physicians Core Content Task Force II. The model of the clinical practice of emergency medicine. Ann Emerg Med 2001;37: 745-70.

2. Wears RL, Perry SJ. Human factors and ergonomics in the emergency department. Ann Emerg Med 2002;40(2):206-12.

3. Spear M. Ergonomics and human factors in health care settings. Ann Emerg Med 2002;40(2):213-6.

4. Weinger MB, Slagle J. Human factors research in anesthesia patient safety. Proc AMIA Symp 2001;750-60.

5. Computerized notepads boost ER physician's efficiency. Health Care Cost Reengineering Rep 1999;4(10):156-8.

6. Hassell I. Working smarter, not harder. Improving emergency department nurse productivity. Emerg Nurse 2001;8(10):7-8.

7. Wyllie JH, Kidson IG, Wyllie DH. Pursuing efficiency in surgical practice. BMJ 1988;297:1368-71.

8. Chisholm CD, Collison EK, Nelson DR, Cordell WH. Emergency department workplace interruptions: Are emergency physicians "interrupt-driven" and "multitasking"? Acad Emerg Med 2000;7(11):1239-43.

9. Beel TL. Speed in the emergency department: doing things faster without sacrificing quality. ACEP News EM Res 2000;4(3):1-2. Available: www.acep.org/1,2421,0.html (accessed 2003 June 4).

10. Vincent C, Simon R, Sutcliffe K, Adams JG, Biros MH, Wears RL. Errors conference: executive summary. Acad Emerg Med 2000;7(11):1180-2.

11. Hoffenberg S, Hill MB, Houry D. Does sharing process differences reduce patient length of stay in the emergency department? Ann Emerg Med 2001;38(5):533-40.

12. Fernandes CMB, Christenson JM. Use of continuous quality improvement to facilitate patient flow through the triage and fasttrack areas of an emergency department. J Emerg Med 1995;13: 847-55.

13. Risser DT, Rice MM, Salisbury ML, Simon R, Jay GD, Berns $\mathrm{SD}$. The potential for improved teamwork to reduce medical errors in the emergency department. Ann Emerg Med 1999;34: 373-83.

14. Croskerry P. The cognitive imperative: thinking about how we think. Acad Emerg Med 2000;7:1223-31.

15. Coiera EW, Jayasuriya RA, Hardy J, Bannan A, Thorpe ME. Communication loads on clinical staff in the emergency department. Med J Aust 2002;176(9):415-8.

16. Shem S. The House of God. New York: Dell; 1978. p. 420.

17. Hollingsworth JC, Chisholm CD, Giles BK, Cordell WH, Nelson DR. How do physicians and nurses spend their time in the emergency department? Ann Emerg Med 1998;31(1):87-91.

18. Hoyt DB, Shackford SR, Fridland PH, Mackersie RC, Hansbrough JF, Wachtel TL. Videorecording trauma resuscitations: an effective teaching technique. J Trauma 1988;28:435-40.

19. DeBehnke D, O'Brien S, Leschke R. Emergency medicine resident work productivity in an academic emergency department. Acad Emerg Med 2000;7(1):72-4.

Correspondence to: Dr. Christopher J. Denny, Institute for Clinical Evaluative Sciences, G1 06, 2075 Bayview Ave., Toronto ON M4N 3M5; fax 416 480-6048, chris.denny @ices.on.ca 